\title{
Synthetic Vessel Graft
}

National Cancer Institute

\section{Source}

National Cancer Institute. Synthetic Vessel Graft. NCI Thesaurus. Code 1117823.

A vessel graft comprised of manufactured material. 